Article

\title{
Porous Curdlan-Based Hydrogels Modified with Copper Ions as Potential Dressings for Prevention and Management of Bacterial Wound Infection-An In Vitro Assessment
}

\author{
Aleksandra Nurzynska ${ }^{1}\left(\mathbb{D}\right.$, Katarzyna Klimek $^{1, *}{ }^{1}$, Iga Swierzycka ${ }^{1}$, Krzysztof Palka $^{2}(\mathbb{D}$ and \\ Grazyna Ginalska ${ }^{1}$ (D) \\ 1 Chair and Department of Biochemistry and Biotechnology, Medical University of Lublin, Chodzki 1 Street, \\ 20-093 Lublin, Poland; 59503@student.umlub.pl (A.N.); iga.swierzycka@interia.pl (I.S.); \\ g.ginalska@umlub.pl (G.G.) \\ 2 Faculty of Mechanical Engineering, Lublin University of Technology, Nadbystrzycka 26 Street, \\ 20-618 Lublin, Poland; k.palka@pollub.pl \\ * Correspondence: katarzyna.klimek@umlub.pl; Tel.: +48-81-448-7028 or +48-81-448-7020
}

Received: 30 July 2020; Accepted: 21 August 2020; Published: 23 August 2020

\begin{abstract}
Bacterial infections at the wound site still remain a huge problem for current medicine, as they may lead to development of chronic wounds. In order to prevent such infections, there is a need to use wound dressings that possess ability to inhibit bacterial colonization. In this study, three new curdlan-based biomaterials modified with copper ions were fabricated via simple and inexpensive procedure, and their structural, physicochemical, and biological properties in vitro were evaluated. Received biomaterials possessed porous structure, had ability to absorb high amount of simulated wound fluid, and importantly, they exhibited satisfactory antibacterial properties. Nevertheless, taking into account all evaluated properties of new curdlan-based biomaterials, it seems that Cur_Cu_8\% is the most promising biomaterial for management of wounds accompanied with bacterial infections. This biomaterial exhibited the best ability to reduce Escherichia coli and Staphylococcus aureus growth and moreover, it absorbed the highest amount of simulated wound fluid as well as enabled optimal water vapor transmission. Furthermore, Cur_Cu_8\% biomaterial possessed the best values of selective indexes, which determine its potential safety in vitro. Thus, Cur_Cu_8\% hydrogel may be considered as a promising candidate for management of infected wounds as well as it may constitute a good platform for further modifications.
\end{abstract}

Keywords: antibacterial dressings; bacterial infections; chronic wounds; copper ions; cytotoxicity; glucans; fibroblasts; skin; wound healing

\section{Introduction}

Microbial growth is considered as a crucial factor, which affects the rate of wound healing [1-4]. Development of bacterial infections at the wound site (especially caused by Staphylococcus aureus, Enterococcus faecalis, Pseudomonas aeruginosa, and Escherichia coli) leads to prolonged inflammation stage, which does not allow for proper wound healing and also may lead to sepsis or even to patient dead [1,4-7].

Prevention of bacterial colonization as well as management of bacterial infections at the wound site require the use of appropriate dressings. Such biomaterials must primarily be non-toxic, non-allergenic, and non-adherent. Moreover, they should be semi-permeable for water and oxygen, should absorb wound exudate, and maintain moist environment at the wound site. Most important, they must prevent bacterial colonization $[1,3,6,8-10]$. Thus, advanced dressings are frequently improved with antimicrobial 
agents such as antibiotics [8,11,12], antiseptics [11,13,14], and metals [11,15-17]. The modification of dressings with metal ions (e.g., silver, zinc, and copper) constitutes promising approach towards management of infected wounds, especially resulted from colonization of antibiotic resistant bacterial strains [15-18]. Among mentioned metal ions, copper has had great attention due to its crucial role in wound healing. It exhibits not only a broad spectrum of antimicrobial activity but also enhance wound healing via promotion of angiogenesis as well as supporting of expression and stabilization of extracellular skin proteins $[7,18]$. It is also worth noting that $\mathrm{Cu}^{2+}$ is cheaper, more oxidation resistant, and more stable in comparison with $\mathrm{Ag}^{+}$[19]. Thus to date, many wound dressings enriched with copper ions have been developed and described in literature $[10,15,16,19-21]$. For instance, Basu et al. [15] fabricated wood-derived nanocellulose hydrogels modified with copper ions and demonstrated that such biomaterials may be considered as promising wound dressings, as they possessed antibacterial activity against both Staphylococcus epidermidis and Pseudomonas aeruginosa. Klinkajon and Supaphol [16] showed that alginate hydrogels cross-linked by copper ions possessed good ability to absorb fluids, had hemostatic properties as well as enabled water vapor transmission. Moreover, some of biomaterials exhibited antibacterial activity against Staphylococcus aureus, Staphylococcus epidermidis, Streptococcus pyogenes, and Escherichia coli. Li et al. [19] presented chitosan- $\mathrm{Cu}^{2+} / \mathrm{NH}_{3}$ physical wound dressings and they proved that such biomaterials possessed weak antibacterial activity against Enterococcus faecalis, Escherichia coli as well as Staphylococcus aureus, but caused strong inhibition of Pseudomonas aeruginosa growth. Meanwhile, Ren et al. [21] fabricated chitosan film enriched with copper metal-organic framework and proved its antibacterial activity in vitro (study on Staphylococcus aureus and Escherichia coli) as well as in vivo (study on Balb/c mice infected by Staphylococcus aureus).

The aim of this study was to determine potential application of curdlan-based hydrogels enriched with copper ions as dressings for prevention of bacterial colonization and for management of infected wounds. Curdlan (linear $\beta-1,3$-glucan) is a non-toxic polymer, synthesized by Agrobacterium sp. This polysaccharide and its derivatives possess wide spectrum of biological actions including immunomodulatory, anti-cancer, anti-coagulant, and anti-infective properties [22]. Furthermore, it has ability to form hydrogel during heat-treatment process (incubation temperature above $55^{\circ} \mathrm{C}$ ) as well as in the presence of divalent ions (such as calcium, copper or zinc) $[23,24]$. Thus, thanks to its beneficial properties, curdlan is willingly used for many medical and pharmaceutical applications [22,25,26]. Nevertheless, to our best knowledge, the biomedical potential of curdlan biomaterial enriched with copper ions has not yet been investigated.

In this study, novel curdlan-based biomaterials were fabricated by cost-effectiveness, simple as well as relatively rapid procedure, which involved ion-exchanging dialysis against copper ions followed by freezing at $-80^{\circ} \mathrm{C}$, and freeze-drying. In assumption, combination of these fabrication techniques should allow to obtain biomaterials, which will have porous structure, will absorb great amount of liquids, and most important will possess antibacterial properties, thanks to copper content. To establish so, structural, physicochemical, antibacterial as well as cytotoxic properties of curdlan-based hydrogels were evaluated.

\section{Materials and Methods}

\subsection{Materials}

Bovine serum albumin (BSA), Live/Dead Cell Double Staining Kit, penicillin-streptomycin solution, phosphate buffered saline (PBS), silica gel with indicator (orange gel), sodium dodecyl sulfate (SDS), thiazolyl blue tetrazolium bromide (MTT), tris-hydroxymethyl aminomethane (TRIS), and trypsin-EDTA solution (0.25\%) were obtained from Sigma-Aldrich Chemicals, Poznań, Poland. Curdlan (MW $80 \mathrm{kDa}$ ) was purchased from Wako pure Chemicals Industries, Osaka, Japan, whereas fetal bovine serum (FBS) from Pan-Biotech, Aidenbach, Germany. Eagle's Minimum Essential Medium (EMEM), normal human skin fibroblasts (BJ cell line, CRL-2522 ${ }^{\mathrm{TM}}$ ), Staphylococcus aureus (ATCC 25923) 
as well as Escherichia coli (ATCC 25922) were supplied by ATCC, London, UK, while Mueller-Hinton agar (MHA) and Mueller-Hinton broth (MHB) by Oxoid, UK. Live/dead BacLight Bacterial Viability Kit

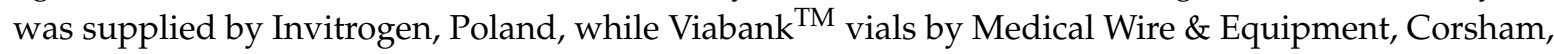
UK. Calcium chloride $\left(\mathrm{CaCl}_{2}\right)$, copper (II) chloride $\left(\mathrm{CuCl}_{2}\right)$, sodium chloride $(\mathrm{NaCl})$, hydrochloric acid $(\mathrm{HCl})$, and sodium hydroxide $(\mathrm{NaOH})$ were purchased from Avantor Performance Materials, Gliwice, Poland. In turn, copper ions detection kit was obtained from BioMaxima, Lublin, Poland.

\subsection{Fabrication of Curdlan-Based Hydrogels Modified with Copper Ions}

The curdlan-based biomaterials were prepared during inexpensive and simple procedure that includes combination of two techniques, i.e., ion-exchanging dialysis against copper ions and freeze-drying. Firstly, the solutions composing of $11 \mathrm{wt} . \%$ of curdlan in $0.3 \mathrm{M}$ aqueous $\mathrm{NaOH}$ were obtained, and then they were transferred into forms (round-shaped with $2.2 \mathrm{~cm}$ in diameter). Subsequently, these solutions were subjected to ion-exchanging dialysis against copper chloride solutions at concentration of $4 \%, 6 \%$, and $8 \%$. After 24 -h incubation at $25^{\circ} \mathrm{C}$, solid biomaterials were rinsed three times with deionized water, blotted with tissue paper, and put into freezer at $-80^{\circ} \mathrm{C}$ for 2 days. In order to obtain dry samples, frozen samples were freeze-dried for $24 \mathrm{~h}$ (LYO GT2-Basic, SRK Systemtechnik GmbH, Riedstadt, Germany). The obtained samples were marked as Cur_Cu_4\%, Cur_Cu_6\%, and Cur_Cu_8\% (Table 1). All samples were sterilized by ethylene oxide.

Table 1. Composition of novel curdlan-based hydrogels modified with copper ions.

\begin{tabular}{ccc}
\hline Sample Code & $\begin{array}{c}\text { Concentration of Curdlan in } \\
\mathbf{0 . 3 ~ M ~ N a O H} \text { Solution (wt.\%) }\end{array}$ & $\begin{array}{c}\text { Concentration of Copper } \\
\text { Chloride Solution Used for } \\
\text { Ion-Exchanging Dialysis (\%) }\end{array}$ \\
\hline Cur_Cu_4\% & 11 & 4 \\
Cur_Cu_6\% & 11 & 6 \\
Cur_Cu_8\% & 11 & 8 \\
\hline
\end{tabular}

\subsection{Assessment of Morphology of the Biomaterials}

The morphology of the biomaterials was evaluated using scanning electron microscopy (Nova NanoSEM 450, FEI, Oxford, UK), equipped with Octane Pro EDS detector (EDAX), which allowed for chemical analysis and identification of elements present on biomaterial surface.

\subsection{Evaluation of Ability of Biomaterials to Absorb Wound Exudate}

This experiment was performed according to guidelines described by Rezvanian et al. [27]. Prior to experiment, the simulated wound fluid (SWF) was prepared. To obtain $1 \mathrm{~L}$ of SWF, the following components were dissolved in deionized water: $2.22 \mathrm{~g}$ of $\mathrm{CaCl}_{2}, 23.38 \mathrm{~g}$ of $\mathrm{NaCl}, 9.69 \mathrm{~g}$ of TRIS, and $20 \mathrm{~g}$ of BSA. The $\mathrm{pH}$ of prepared solution was adjusted to 7.5. Then, three independent biomaterial samples $(n=3)$ were weighted, and soaked in simulated wound fluid (SWF) at room temperature. After appropriate time period, biomaterials were removed from SWF, blotted with tissue paper, weighted, and re-immersed in solution. The experiment was carried out for $24 \mathrm{~h}$. The ability of biomaterials to swell in SWF was expressed as swelling ratio that was calculated as follows:

$$
\mathrm{SW}(\%)=\frac{(\mathrm{Ws}-\mathrm{Wd})}{\mathrm{Wd}} \times 100
$$

where Ws is a weight of wet biomaterials and $\mathrm{Wd}$ is a weight of dry ones.

\subsection{Evaluation of Water Vapor Transmission Rate}

Ability of biomaterials to transmit water vapor was evaluated according to procedure described by Rezvanian et al. [28] with some modifications. Prior to test, $5 \mathrm{~g}$ of silica gel with indicator was put 
into glass vials (diameter of mouth of vial was $1 \mathrm{~cm}$ ) and dried for $24 \mathrm{~h}$ at $60^{\circ} \mathrm{C}$ (Drying oven SUP-65, Wamed). At the same time, three independent biomaterial samples $(n=3)$ were immersed in SWF ( $24 \mathrm{~h}$, room temperature) in order to obtain totally soaked samples. Then, the vials (with dry silica gel) were weighted. The biomaterials were taken out of solution, blotted with tissue paper, and precisely mounted on the mouth of vials using rubber rings to prevent any water vapor influx through the boundary. The vials with biomaterials were transferred to the incubator (Heraeus cytoperm 2, Thermo Scientific, Waltham, MA, USA) for $24 \mathrm{~h}\left(37^{\circ} \mathrm{C}, 95 \%\right.$ relative humidity). After this time, the biomaterials from vials were removed and the vials with wet silica gel were weighted. The water vapor transmission rate (WVTR) was calculated using the following formula:

$$
\operatorname{WVTR}\left(\mathrm{g} / \mathrm{m}^{2} / \text { day }\right)=\frac{\mathrm{Ww}-\mathrm{Wd}}{\mathrm{S}}
$$

where $\mathrm{Ww}$ is a weight of vial with wet silica gel (after 24-h incubation), Wd is a weight of vial with dry silica gel (before incubation), and $\mathrm{S}$ is surface area of mouth of vial $\left(\mathrm{m}^{2}\right)$.

\subsection{Measurement of Concentration of Copper Ions Released from Biomaterials}

The ability of biomaterials to release copper ions into an aqueous environment was assessed using two culture media, i.e., Mueller-Hinton broth (MHB) and Eagle's Minimum Essential Medium (EMEM), which are dedicated for culture of bacteria or skin fibroblasts, respectively. For this purpose, three independent biomaterial specimens $(n=3)$ were weighted, placed into 12-well plate, and incubated with MHB or EMEM at $37^{\circ} \mathrm{C}$ for $24 \mathrm{~h}$. The extraction ratio was $0.1 \mathrm{~g}$ of biomaterial per $1 \mathrm{~mL}$ of appropriate medium. This proportion is recommended by ISO 10993-5: 2009 standard [29]. In order to obtain control extracts, MHB or EMEM were incubated without biomaterials. The concentration of copper ions in collected liquid extracts was assessed using copper ions detection kit, according to manufacturer protocol. This kit based on direct colorimetric method using 3,5-DiBr-PAESA (4-(3,5-dibromo-2-pyridylazo)-N-ethyl-N-sulfopropylaniline monosodium salt, monohydrate). The copper ions react with 3,5-DiBr-PAESA and form stable blue complex. The absorbance of this complex was measured at $582 \mathrm{~nm}$ and it is proportional to the concentration of copper in the sample.

\subsection{Antibacterial Activity of Biomaterials}

The bacterial strains were stored at $-70{ }^{\circ} \mathrm{C}$ in Viabank ${ }^{\mathrm{TM}}$ vials. Before each experiments, the bacteria-Staphylococcus aureus (S. aureus) and Escherichia coli (E. coli) were subcultured on MHA plates at $37^{\circ} \mathrm{C}$ for $24 \mathrm{~h}$. Afterwards, bacterial colonies were suspended in MHB. The bacterial suspensions were adjusted to the turbidity of a 0.5 McFarland standard (PhoenixSpec Nephelometer, Becton Dickinson, Franklin Lakes, NJ, USA).

\subsubsection{Determination of Zones of Bacterial Growth Inhibition}

In order to assess the preliminary antibacterial activity of investigated biomaterials, the disc diffusion method was applied [30]. For this purpose, prepared bacterial inoculums (S. aureus or E. coli) were spread over the Petri Dishes containing MHA using sterile cotton swabs. Then, biomaterial specimens were placed onto MHA with inoculated bacteria and such Petri Dishes were transferred to the incubator $\left(37^{\circ} \mathrm{C}, 24 \mathrm{~h}\right)$. After this time, the zones of bacterial growth inhibition around the biomaterial samples were measured. The experiment was carried out in three replicates $(n=3)$.

\subsubsection{Evaluation of Inhibition of Bacterial Growth in Direct Contact with Biomaterials}

Prior to experiment, six independent biomaterial samples $(n=6)$ were placed in 12 -well plates. Then, $2 \mathrm{~mL}$ of the appropriate bacterial suspension (S. aureus or E. coli) was added directly to each biomaterial samples. The bacterial inoculates added to wells without biomaterials were served as controls. The plates were incubated at $37^{\circ} \mathrm{C}$ for $24 \mathrm{~h}$. The inhibition of bacterial growth in 
the direct contact with biomaterials was assessed qualitatively. Therefore, after incubation time, the bacterial suspensions from the wells without biomaterials (control) or with biomaterials were collected, centrifuged (13,000 rpm, $10 \mathrm{~min}$ ), suspended in $40 \mu \mathrm{L}$ of fresh MHA, and stained with Live/dead BacLight Bacterial Viability Kit according to manufacturer procedure. Briefly, this kit is composed of two fluorescent dyes, i.e., SYTO 9 and propidium iodide. Firstly, stock solution of dyes in $0.9 \% \mathrm{NaCl}$ was prepared ( $1 \mu \mathrm{L}$ of SYTO $9+1 \mu \mathrm{L}$ of propidium iodide $+8 \mu \mathrm{L}$ of $\mathrm{NaCl}$ solution). Then, $1 \mu \mathrm{L}$ of such stock solution was added to $40 \mu \mathrm{L}$ of bacterial suspension. After $15 \mathrm{~min}$. incubation at $37^{\circ} \mathrm{C}$, the dyed bacteria were transferred on glass microscope slides and observed under confocal laser scanning microscope (CLSM, Olympus Fluoview equipped with FV1000, Olympus, Tokyo, Japan Manufacturer, City, Country). The excitation/emission maxima for SYTO 9 and propidium iodide are about 480/500 $\mathrm{nm}$ and 490/638 nm, respectively. Thus, live bacteria (stained with SYTO 9) emitted green fluorescence, whereas dead ones (stained with propidium iodide) emitted red fluorescence.

\subsubsection{Evaluation of Inhibition of Bacterial Growth in Indirect Contact with Biomaterials-Test on Extracts}

This experiment was carried out according to general procedure described by Siek et al. [31], but with some modifications. Thus, the influence of fluid extracts obtained from the biomaterials $(n=3)$ on bacterial growth was investigated. Such extracts were prepared using MHB as described in Section 2.6. Received extracts $(100 \%)$ were then diluted in fresh MHB (ranged from $90-10 \%$ ) in order to mimic experiment conditions, which were applied during cytotoxicity evaluation (Section 2.8). Then, $100 \mu \mathrm{L}$ of appropriate extracts (100-10\%) were placed into 96-well plates and $10 \mu \mathrm{L}$ of bacterial inoculates (S. aureus or E. coli) were added. As a control extract, pure MHA incubated without biomaterials was used. After 24-h incubation, $100 \mu \mathrm{L}$ of bacterial suspensions (three repetitions of each groups) were seeded on Petri Dishes containing MHA, and the plates were transferred into incubator $\left(37^{\circ} \mathrm{C}\right)$. On the next day, bacterial colonies were counted and the results were expressed as a $\%$ of $\log _{10} \mathrm{CFU} / \mathrm{mL}$ of control bacteria. Based on these data, values of concentration of extract $\left(\mathrm{CE}_{50}\right)$ were calculated via 4-parameter nonlinear regression analyses (GraphPad Prism 5, Version 5.04, GraphPad, San Diego, CA, USA). The $\mathrm{CE}_{50}$ means concentration of extract required for reduction of $S$. aureus or E. coli growth to $50 \%$.

\subsection{Cytotoxicity Evaluation and Determination of Selective Index}

Cytotoxic activity of tested biomaterials was evaluated by indirect method, i.e., using fluid extracts obtained from biomaterials $(n=3)$. Firstly, the BJ cells were seeded in 96-well plates in $100 \mu \mathrm{L}$ of EMEM at concentration of $1.5 \times 10^{5}$ cells $/ \mathrm{mL}$ and incubated at $37^{\circ} \mathrm{C}$ for $24 \mathrm{~h}$. At the same time, liquid extracts from biomaterials were prepared in EMEM as described in Section 2.6. Obtained extracts $(100 \%)$ were further diluted in fresh EMEM (ranged from 90-10\%). As a control extract, pure EMEM incubated without biomaterials was used. Then, culture medium was gently removed and $100 \mu \mathrm{L}$ of appropriate extracts (100-10\%) or control extract were added to the BJ cells. After 24-h incubation, cell viability was assessed both quantitatively (via MTT assay) and qualitatively (via cell staining with Live/Dead Cell Double Staining Kit). The MTT test was performed according to procedure described earlier [32]. Received results were expressed as \% of viability of control cells. Based on these data, values of $\mathrm{CE}_{50}$ were calculated (4-parameter nonlinear regression analyses, GraphPad Prism 5, version 5.04). The $\mathrm{CE}_{50}$ means concentration of extract required for reduction of viability of $\mathrm{BJ}$ cells to $50 \%$. In turn, values of selective index (SI) were calculated as follows:

$$
\mathrm{SI}=\frac{\mathrm{CE}_{50} \text { for fibroblast cells }}{\mathrm{CE}_{50} \text { for bacterial cells }}
$$

The BJ cell viability after staining with Live/Dead Cell Double Staining Kit (in accordance with manufacturer protocol) was assessed using CLSM (Olympus Fluoview equipped with FV1000). Live fibroblasts emitted green fluorescence, whereas dead ones emitted red fluorescence. 


\subsection{Statistical Analysis}

All experiments were performed using at least three independent biomaterial samples and the obtained results were presented as mean values \pm standard deviation (SD). In order to determine the statistically significant differences between groups $(p<0.05)$, one-way ANOVA test followed by Tukey's multiple comparison test was performed using GraphPad Prism 5, Version 5.04 Software.

\section{Results and Discussion}

\subsection{Morphology of Biomaterials}

Performed SEM analysis revealed that all biomaterials possessed rough and porous structure (Figure 1). Porous structure is considered as an important property of biomaterial because it significantly increases its specific surface area. It was demonstrated that the higher specific surface area is, the biomaterial has better absorbent properties [33]. Therefore, it seems that novel porous curdlan-based biomaterials should exhibit good ability to swell in the contact with liquids. In turn, EDS spectra (Figure 1) revealed that biomaterial surfaces were rich in copper precipitates, what confirms that dialysis method against $\mathrm{CuCl}_{2}$ solution enables successful incorporation of copper into curdlan-based biomaterials. Taking together, it is worth to underline that combination of two techniques, i.e., ion exchanging dialysis followed by freezing, and freeze-drying allows to obtain porous biomaterials which are enriched with copper.
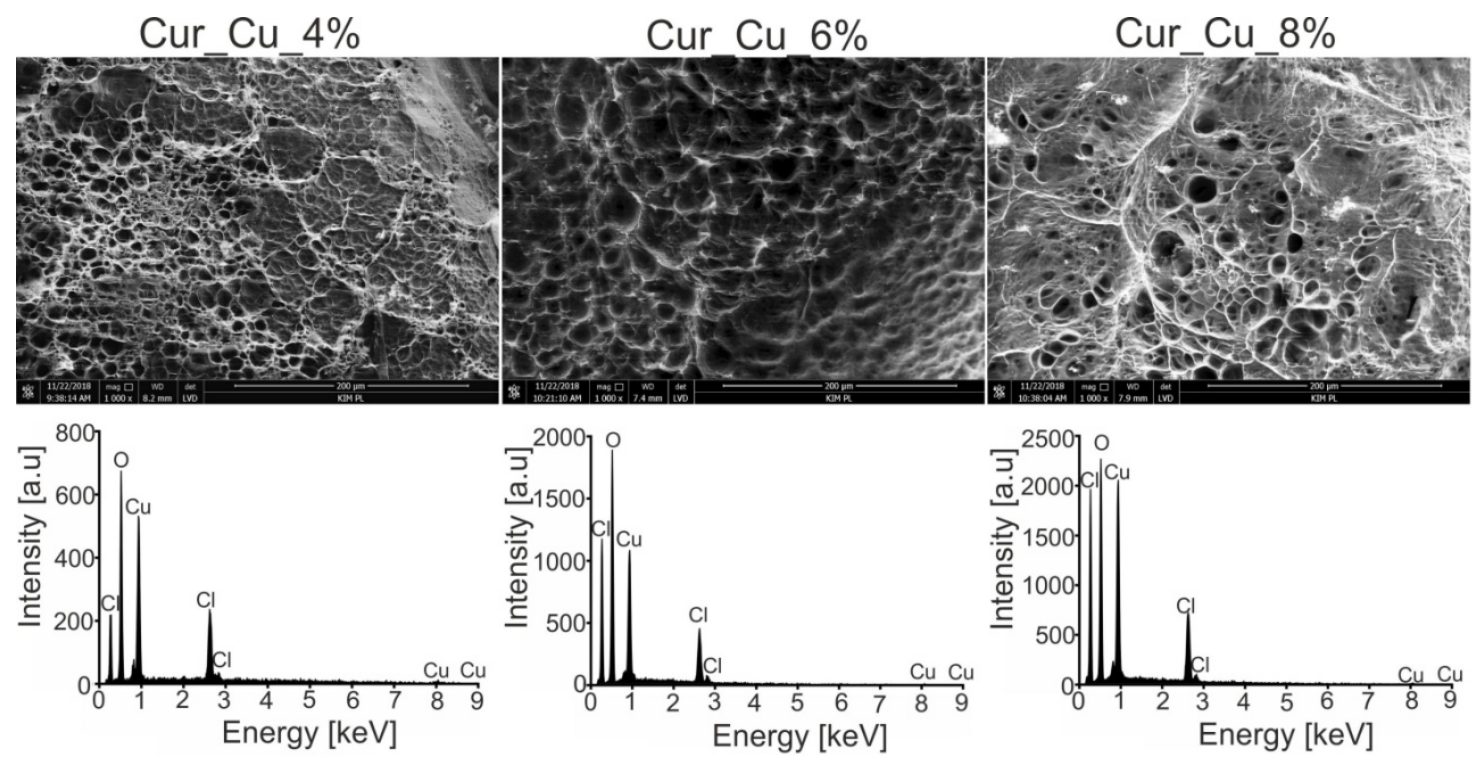

Figure 1. Scanning electron microscopy (SEM) images and energy dispersive spectroscopy (EDS) spectra of Cur_Cu_4\%,Cur_Cu_6\%, and Cur_Cu_8\%. Magnification of SEM images: 1000×.

\subsection{Absorption Capacity of Biomaterials}

The test carried out in SWF demonstrated that throughout the experiment period, Cur_Cu_8\% absorbed the highest amount of liquid, whereas the amount of SWF absorbed by Cur_Cu_4\% was the slightest (Figure 2). At the end of test (after 24-h incubation), the swelling ratios for biomaterials were $209.60 \pm 29.99 \%$ (Cur_Cu_4\%), $288.80 \pm 29.99 \%$ (Cur_Cu_6\%), and $397.20 \pm 20.80 \%$ (Cur_Cu_8\%). The suitable dressing for chronic wounds should absorb high amount of exudate, which can achieve even $12 \mathrm{~L} / \mathrm{m}^{2}$ [34]. When compared investigated curdlan-based dressings with others biomaterials dedicated for treatment of chronic wounds, it is clear that newly fabricated biomaterials have good ability to absorb liquids. For instance, the agar-sericin hydrogel film dressings dedicated for chronic wounds possessed swelling ratios that were around 320\% [35], while the ability of alginate-pectin hydrogel films to absorb SWF was slightly above $250 \%$ [27]. Thus, these results indicate that porous 
curdlan-based biomaterials, especially $\mathrm{Cur} \_\mathrm{Cu} \_6 \%$ as well as $\mathrm{Cur} \_\mathrm{Cu} \_8 \%$ exhibit optimal liquid absorption capacity for wounds with moderate to high exudate levels.

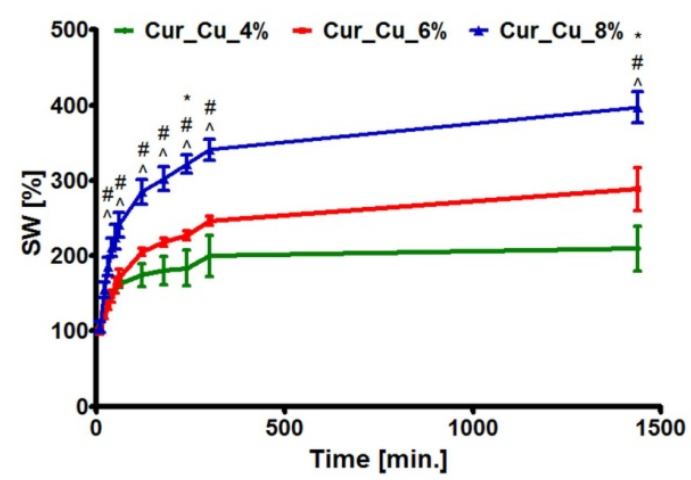

Figure 2. The ability of Cur_Cu_4\%,Cur_Cu_6\%, and Cur_Cu_8\% samples to swell in simulated wound fluid during 24-h incubation. \#-significantly different results between Cur_Cu_6\% and Cur_Cu_8\%, ^-significantly different results between Cur_Cu_4\% and $\mathrm{Cur} \_\mathrm{Cu} \_8 \%$, ${ }^{-}$- significantly different results between Cur_Cu_4\% and Cur_Cu_6\%; one-way ANOVA followed by Tukey's multiple comparison test, $p<0.05$.

\subsection{Water Vapor Transmission Rate of Biomaterials}

Water vapor transmission test (Figure 3) showed that fabricated curdlan-based biomaterials possessed WVTR close to approx. $1894 \mathrm{~g} / \mathrm{m}^{2} /$ day (Cur_Cu_4\%), $1964 \mathrm{~g} / \mathrm{m}^{2} /$ day (Cur_Cu_6\%), and $2009 \mathrm{~g} / \mathrm{m}^{2} /$ day (Cur_Cu_8\%). According to available data, the appropriate dressings should inhibit excessive dehydration of skin, but they should also enable skin to "breath". For these reasons, the WVTR for dressings should achieve $2000-2500 \mathrm{~g} / \mathrm{m}^{2} /$ day $[27,36]$. Thus, among obtained samples, only Cur_Cu_8\% biomaterial exhibited optimal value of WVTR (above $2000 \mathrm{~g} / \mathrm{m}^{2} /$ day).

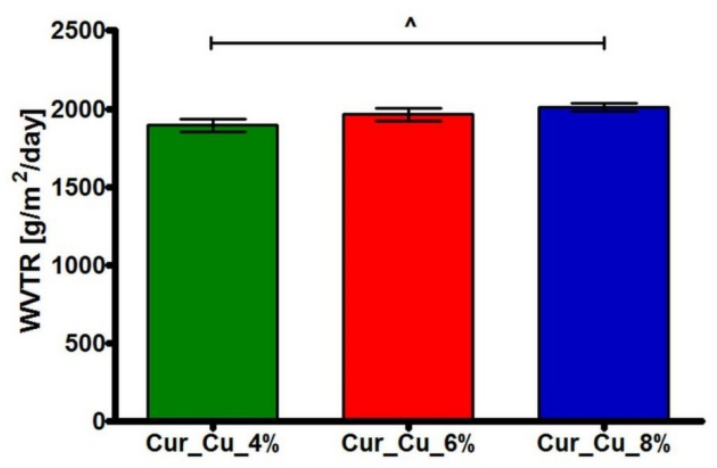

Figure 3. The ability of Cur_Cu_4\%,Cur_Cu_6\%, and Cur_Cu_8\% samples to transmit water vapor during 24-h experiment. ^—significantly different results between Cur_Cu_4\% and Cur_Cu_8\%; one-way ANOVA followed by Tukey's multiple comparison test, $p<0.05$.

\subsection{Ability of Biomaterials to Release Copper Ions}

The release test showed that concentration of copper ions in extracts obtained from all tested biomaterials was significantly higher $(p<0.05)$ compared to concentration of these ions in control extracts-media incubated without biomaterials (Figure 4a,b). Among tested dressings, Cur_Cu_8\% possessed the greatest ability to release copper ions. Thus, after 24-h incubation in MHB or EMEM, the concentration of copper ions released from Cur_Cu_8\% was $268.30 \pm 15.84 \mathrm{mg} / \mathrm{L}$ (Figure 4a) and $220.50 \pm 10.82 \mathrm{mg} / \mathrm{L}$ (Figure $4 \mathrm{~b}$ ), respectively. It is worth to note that applied culture medium (MHB or EMEM) did not significantly affect ability of biomaterials to release copper ions, what is a crucial for reliable evaluation of antibacterial and cytotoxic activities of biomaterials. 

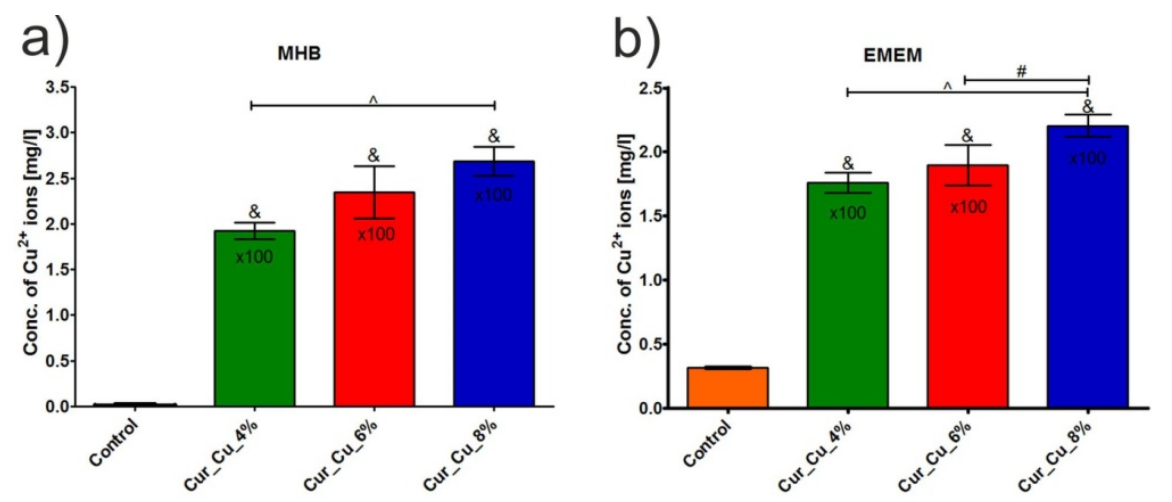

Figure 4. Concentration of copper ions in extracts obtained from Cur_Cu_4\%, Cur_Cu_6\%, and Cur_Cu_8\% biomaterials after 24-h incubation in culture media: (a) Mueller-Hinton broth (MHB) and (b) Eagle's Minimum Essential Medium (EMEM). \&-significantly different results compared to control (media incubated without biomaterials), \#-significantly different results between Cur_Cu_6\% and Cur_Cu_8\%, ^-significantly different results between Cur_Cu_4\% and Cur_Cu_8\%; one-way ANOVA followed by Tukey's multiple comparison test, $p<0.05$.

\subsection{Antibacterial Activity of Biomaterials}

Preliminary antibacterial test (disc diffusion method) demonstrated that all biomaterials possessed ability to inhibit E. coli and S. aureus growth (Figure 5). Nevertheless, it was observed that antibacterial properties of biomaterials increased in the following trend: Cur_Cu_4\% $<$ Cur_Cu_6\% $<$ Cur_Cu_8\%. Thus, the greatest zones of bacterial growth inhibition ( $34 \mathrm{~mm}$ for $E$. coli and $28 \mathrm{~mm}$ for S. aureus) were observed for Cur_Cu_8\%, what most likely resulted from its the best ability to release copper ions (Figure 4).

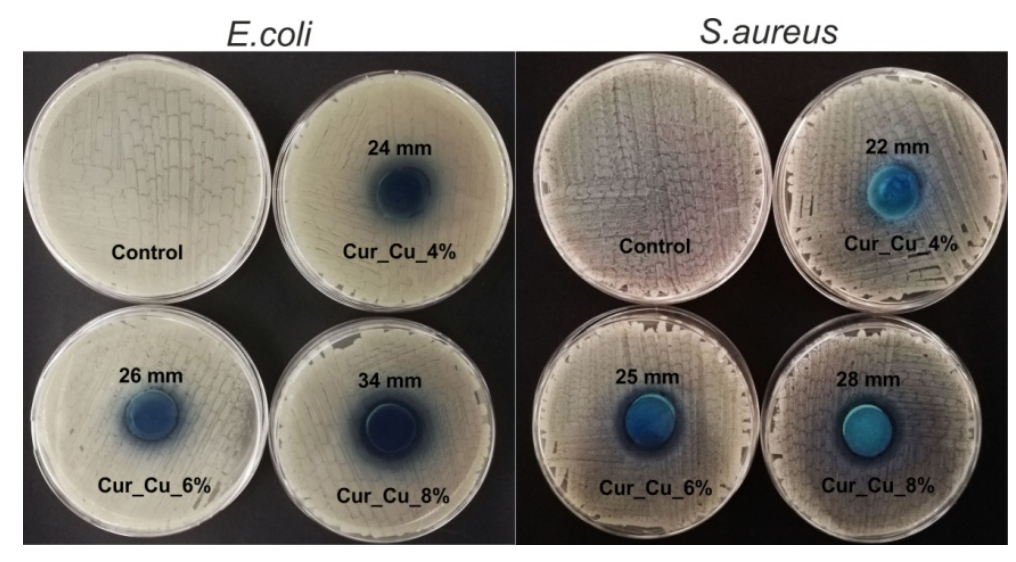

Figure 5. Representative images presenting zones of E. coli and S. aureus growth inhibition around Cur_Cu_4\%,Cur_Cu_6\%, and Cur_Cu_8\% biomaterials. The diameter of samples was equal to $22 \mathrm{~mm}$.

In the next step, the ability of biomaterials to inhibit bacterial growth in liquid medium (MHB) was evaluated via cell staining with Live/dead BacLight Bacterial Viability Kit. Performed microscope observations (Figure 6) clearly confirmed the results obtained during screening antibacterial test (Figure 5), indicating that all dressings had antibacterial activity. After 24-h incubation with biomaterials, the number of E. coli as well as S. aureus was significantly lower compared to number of control bacterial cells (cell incubated without biomaterials) (Figure 6). Despite the visible reduction of amount of viable bacteria after direct contact with biomaterials, none dead bacterial cells were observed, what indicates that $\mathrm{Cur} \_\mathrm{Cu} \_4 \%$, Cur_Cu_6\%, and Cur_Cu_8\% possess bacteriostatic properties but not bactericidal ones. 


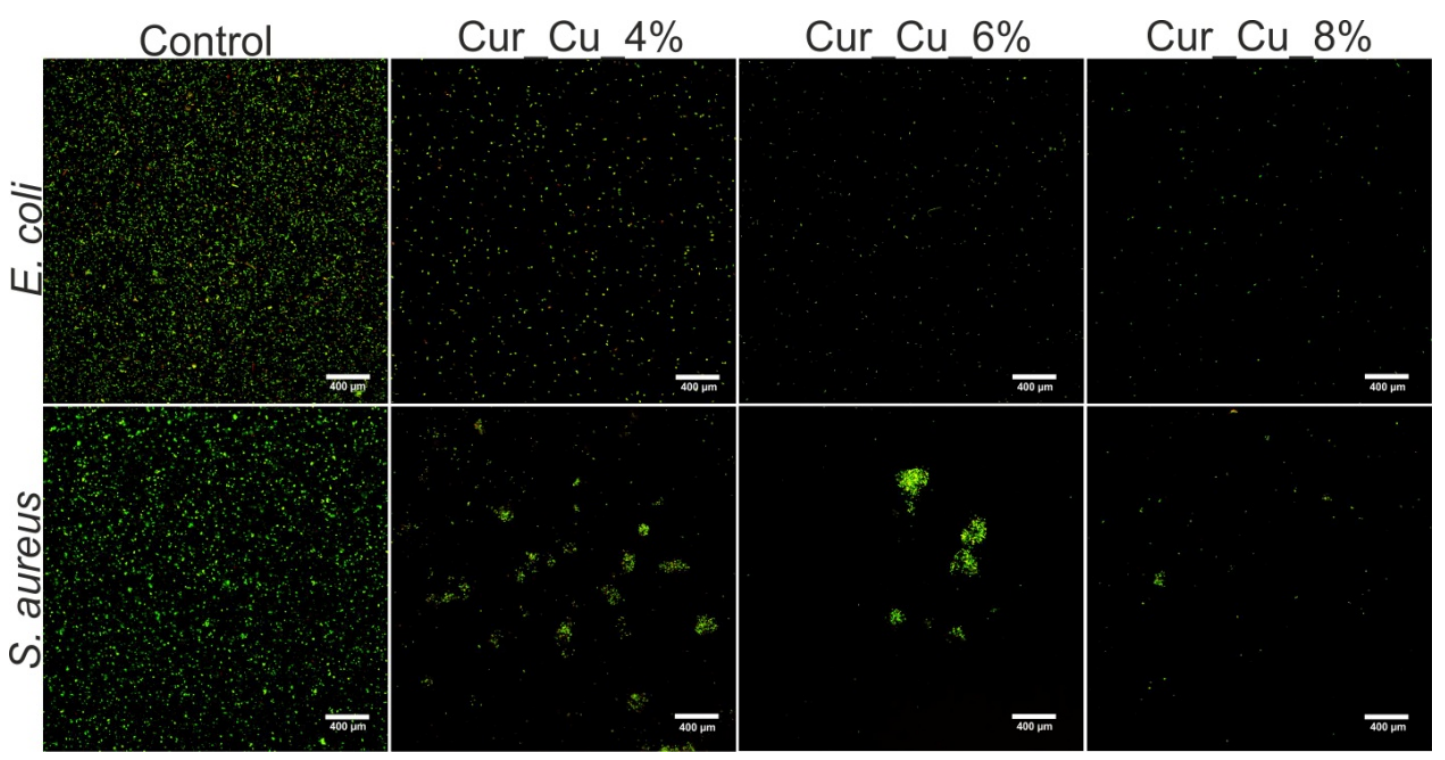

Figure 6. Representative images showing live (green fluorescence) bacteria-E. coli and S. aureus-after 24-h incubation with Cur_Cu_4\%,Cur_Cu_6\%, and Cur_Cu_8\% biomaterials. The bacteria incubated without biomaterials were served as control of experiment. In all tested groups, none dead cells (red fluorescence) were visible. Magnification 400×, scale bar equals $400 \mu \mathrm{m}$.

The last experiment included evaluation of antibacterial properties of extracts obtained from biomaterials. All extracts obtained from tested biomaterials exhibited greater ability to reduce number of E. coli compared to $S$. aureus (Figure 7), what clearly proved the results obtained during previous experiments (Figure 5). It was also demonstrated that extracts obtained from Cur_Cu_8\% possessed the best ability to inhibit both E. coli and S. aureus growth (Figure 7).
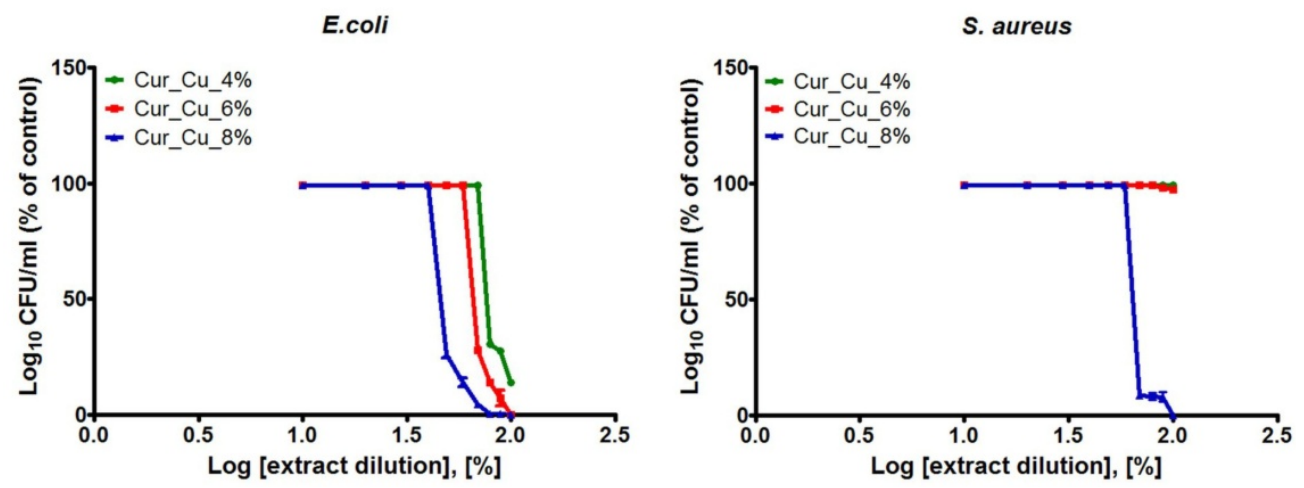

Figure 7. The antibacterial activity of extracts obtained from $\mathrm{Cur} \_\mathrm{Cu} \_4 \%, \mathrm{Cur} \_\mathrm{Cu} \_6 \%$, and $\mathrm{Cur} \_\mathrm{Cu} \_8 \%$ biomaterials. The initial extracts $(100 \%)$ were diluted in fresh MHB $(90-10 \%)$ in order to determine bacterial response to extract solutions at different concentrations.

Based on antibacterial results obtained for different concentrations of extracts (Figure 7), the values of $\mathrm{CE}_{50}$ were calculated (Table 2). It was demonstrated that extracts obtained from Cur_Cu_4\% and Cur_Cu_6\% possessed moderate activity against E. coli ( $\mathrm{CE}_{50}$ close to $76 \%$ and $67 \%$, respectively), while they did not reduce $S$. aureus growth. In turn, extracts obtained from Cur_Cu_8\% possessed the best ability to inhibit bacterial growth, with $\mathrm{CE}_{50}$ values equal to $46.65 \pm 2.21 \%$ (E. coli) and $65.86 \pm 2.12 \%$ (S. aureus). These results indicated that not only direct contact with Cur_Cu_8\% biomaterial provide antibacterial protection, but also released from biomaterial copper ions possess ability to reduce number of bacterial cells. 
Table 2. The concentration of extract $\left(\mathrm{CE}_{50}\right)$ obtained from $\mathrm{Cur} \_\mathrm{Cu} \_4 \%$, $\mathrm{Cur} \_\mathrm{Cu} \_6 \%$, and $\mathrm{Cur} \_\mathrm{Cu} \_8 \%$ biomaterials, which is required to inhibit $E$. coli or $S$. aureus growth to $50 \%$. The $\mathrm{CE}_{50}$ values were calculated via 4-parameter nonlinear regression analyses, GraphPad Prism 5, version 5.04).

\begin{tabular}{ccc}
\hline \multirow{2}{*}{$\begin{array}{c}\text { Biomaterial Used to Obtain } \\
\text { Extract in Mueller-Hinton Broth } \\
\text { (MHB) }\end{array}$} & $\begin{array}{c}\text { Concentration of Extract Required to Inhibit Bacterial Growth to 50\% } \\
\left(\mathbf{C E}_{\mathbf{5 0}}\right) \text { [\%] }\end{array}$ \\
\cline { 2 - 3 } & E. coli & S. aureus \\
\hline Cur_Cu_4\% & $76.48 \pm 1.45$ & ND $^{*}$ \\
Cur_Cu_6\% & $66.73 \pm 2.34$ & ND $^{*}$ \\
Cur_Cu_8\% & $46.65 \pm 2.21$ & $65.86 \pm 2.12$ \\
\hline
\end{tabular}

* ND—not determined. All tested concentrations of extract did not exhibit ability to inhibit bacterial growth to $50 \%$.

Taking together, three independent experiments: disc diffusion test, test in direct contact, and test on extracts clearly showed that Cur_Cu_8\% biomaterial possessed the most beneficial, antibacterial properties. In many research studies, antibacterial properties of biomaterials have been assessed only via disc diffusion method. It is well known, that chronic wounds are associated with high amount of exudate. Thus, released antibacterial agents from biomaterial may be diluted by secreted exudate. For this reason, it is crucial to determine whether dilution of antibacterial agents allows to preserve antibacterial protection. Our research proved that $\mathrm{Cur} \_\mathrm{Cu} \_8 \%$ dressing as well as released by it copper ions should provide antibacterial protection during management of wounds with moderate to high exudate levels.

\subsection{Cytotoxic Activity of Biomaterials}

The MTT assay (Figure 8) as well as Live/Dead Cell Double Staining Kit (Figure 9) revealed that initial extracts obtained from all tested biomaterials were highly toxic towards normal human skin fibroblasts. After 24 -h incubation with extracts (100\%), BJ cell viability was approximately $0.5 \%$. It was also observed that cells were mostly dead (emitting red fluorescence) and only single live cells (emitting green fluorescence) were visible (Figure 9). Dilution of extracts caused that viability of BJ cells significantly increased (Figures 8 and 9).

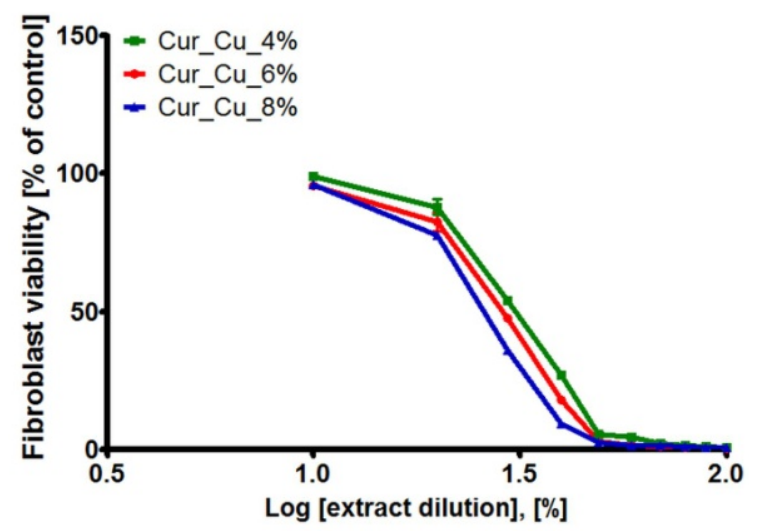

Figure 8. The cytotoxic activity of extracts obtained from $\mathrm{Cur} \_\mathrm{Cu} \_4 \%$, $\mathrm{Cur} \_\mathrm{Cu} \_6 \%$, and $\mathrm{Cur} \_\mathrm{Cu} \_8 \%$ biomaterials. The initial extracts $(100 \%)$ were diluted in fresh Eagle's Minimum Essential Medium (EMEM) $(90-10 \%)$ in order to determine skin fibroblast (BJ cell line) response to extract solutions at different concentrations. 


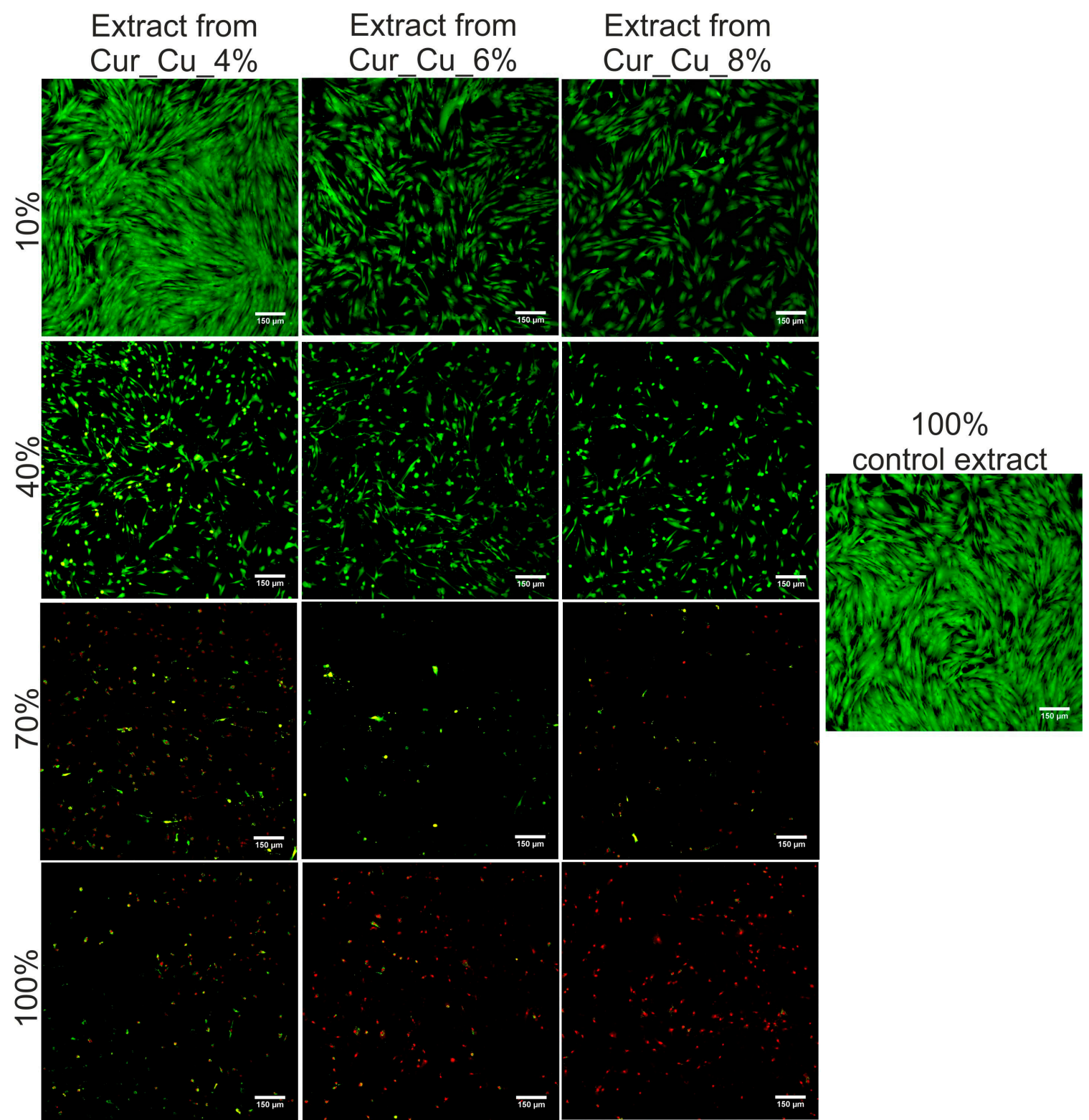

Figure 9. Representative images showing live (green fluorescence) and dead (red fluorescence) BJ cells after 24-h incubation with different concentration of extracts from Cur_Cu_4\%,Cur_Cu_6\%, and Cur_Cu_ $8 \%$ biomaterials. Pure culture medium incubated without biomaterials was served as control extract. Magnification 100×, scale bar equals $150 \mu \mathrm{m}$.

According to ISO recommendations [29], if initial extract (100\%) reduces cell viability below 70\% compared to control, it should be diluted and its concentration required to inhibit cell viability to $50 \%$ $\left(\mathrm{CE}_{50}\right)$ should be determined. Thus, the values of $\mathrm{CE}_{50}$ for $\mathrm{BJ}$ cells were calculated and summarized in Table 3. It was shown that extracts from tested biomaterials exhibited cytotoxic activity, with $\mathrm{CE}_{50}$ ranging 26-30\%. Nevertheless, in order to determine which biomaterial seems to be the most safe in vitro, the SI values were calculated (Table 3 ). Obtained results clearly demonstrated that among tested samples, Cur_Cu_8\% biomaterial exhibits the best SI values (0.56 and 0.40$)$. 
Table 3. The concentration of extract $\left(\mathrm{CE}_{50}\right)$ obtained from $\mathrm{Cur} \_\mathrm{Cu} \_4 \%, \mathrm{Cur} \_\mathrm{Cu} \_6 \%$, and $\mathrm{Cur} \_\mathrm{Cu} \_8 \%$ biomaterials, which is required to inhibit fibroblast viability (BJ cells) to $50 \%$. The $\mathrm{CE}_{50}$ values were calculated via 4-parameter nonlinear regression analyses, GraphPad Prism 5, version 5.04). The values of selective index were calculated based on results obtained for bacteria and fibroblasts. The higher value of Selective Index (SI) is, the extract from biomaterial is safer for eukaryotic cells.

\begin{tabular}{cccc}
\hline Biomaterial Used to Obtain & $\begin{array}{c}\text { Concentration of Extract } \\
\text { Extract in Eagle's Minimum } \\
\text { Essential Medium (EMEM) }\end{array}$ & $\begin{array}{c}\text { Required to Inhibit Fibroblast } \\
\text { Viability to } \mathbf{5 0 \%}\left(\mathrm{CE}_{50}\right)[\%]\end{array}$ & $\begin{array}{c}\text { Selective Index (SI) * } \\
\text { SI }=\frac{\text { CE}_{50} \text { for fibroblast cells }}{\text { CE }_{50} \text { for bacterial cells }}\end{array}$ \\
\cline { 3 - 4 } & $30.91 \pm 1.23$ & 0.40 & E. coli $^{* *}$ \\
\hline Cur_Cu_4\% & $29.49 \pm 1.43$ & 0.44 & ND $^{* *}$ \\
\hline Cur_Cu_6\% & $26.48 \pm 1.73$ & 0.56 & 0.40 \\
\hline
\end{tabular}

* The values of $\mathrm{CE}_{50}$ for bacterial cells were adopted from Table 2. ${ }^{* *} \mathrm{ND}-$ not determined. It was not possible to obtain SI value due to lack of value of $\mathrm{CE}_{50}$ for bacterial cells.

Due to high cytotoxicity in vitro of fabricated biomaterials, their biomedical potential as wound dressings seems to be limited. Biocompatibility of biomaterial is a mandatory feature, which allows to consider its potential medical applications [6,23]. It is worth to underline that biomaterials enriched by metal ions most often exhibit antimicrobial activity, but also they are very toxic towards eukaryotic cells [37]. Received Cur_Cu_4\%,Cur_Cu_6\%, and Cur_Cu_8\% biomaterials possessed good antibacterial activity, so it was expected that they also can be cytotoxic. For these reasons, additional in vivo research are necessary to precise determination of toxic activity of these biomaterials. Moreover, obtained results suggest that there is a need to develop modified curdlan-based dressings, which will have antibacterial properties and will not significantly decrease fibroblast viability. One interesting way includes modification of biomaterials with metal ions combined with plant extracts [38]. Thus, in future our research will be focused on modification of curdlan-based biomaterials with metal ions important for wound healing (e.g., $\mathrm{Cu}^{2+}, \mathrm{Zn}^{2+}$ ) in combination with antimicrobial and non-toxic plant extracts.

\section{Conclusions}

In this study, curdlan-based biomaterials modified by copper ions were fabricated via an inexpensive as well as a relatively simple procedure, which involved ion-exchanging dialysis followed by freezing and freeze-drying. Received biomaterials possessed porous structure (as proven by SEM analysis), exhibit good ability to absorb simulated wound fluid, and had capacity to release a high amount of copper ions to the aqueous environment. Among tested samples, Cur_Cu_8\% had the best physicochemical and antibacterial properties, as it enabled water vapor transmission on optimal level and significantly reduces E. coli and S. aureus growth. Moreover, comparison of antibacterial and cytotoxic activities (expressed as selective indexes), indicated that of $\mathrm{Cur} \_\mathrm{Cu} \_8 \%$ biomaterial exhibited the highest in vitro safety compared to other samples.

Author Contributions: Conceptualization, K.K.; methodology, K.K. and K.P.; software, A.N.; K.K., and K.P.; validation, A.N., K.K., and K.P.; formal analysis, A.N. and K.K.; investigation, A.N.; K.K.; I.S., and K.P.; resources, G.G.; data curation, A.N. and K.K.; writing-original draft preparation, A.N. and K.K.; writing-review and editing, K.K.; visualization, A.N.; supervision, G.G.; project administration, G.G.; funding acquisition, G.G. All authors have read and agreed to the published version of the manuscript.

Funding: This research was funded by DS2 project of Medical University of Lublin, Poland. This paper was developed using the equipment purchased within agreement No. POPW.01.03.00-06-010/09-00 Operational Program Development of Eastern Poland 2007-2013, Priority Axis I, Modern Economy, Operations 1.3. Innovations Promotion.

Acknowledgments: The authors would like to thank Michal Wojcik from Department of Biochemistry and Biotechnology, Medical University of Lublin, Poland for the help with confocal laser scanning microscopy (CLSM) analysis. 
Conflicts of Interest: The authors declare no conflict of interest.

\section{References}

1. Jaganathan, S.K.; Mani, M.P. Electrospun polyurethane nanofibrous composite impregnated with metallic copper for wound-healing application. 3 Biotech 2018, 8, 1-12. [CrossRef] [PubMed]

2. Cardona, A.F.; Wilson, S.E. Skin and Soft-Tissue Infections: A Critical Review and the Role of Telavancin in Their Treatment. Clin. Infect. Dis. 2015, 61, S69-S78. [CrossRef] [PubMed]

3. Han, G.; Ceilley, R. Chronic Wound Healing: A Review of Current Management and Treatments. Adv. Ther. 2017, 34, 599-610. [CrossRef] [PubMed]

4. Landis, S.J. Chronic wound infection and antimicrobial use. Adv. Skin Wound Care 2008, 21, 531-540. [CrossRef] [PubMed]

5. Harriott, M.M.; Bhindi, N.; Kassis, S.; Summitt, B.; Perdikis, G.; Wormer, B.A.; Rankin, T.M.; Kaoutzanis, C.; Samaha, M.; Stratton, C.; et al. Comparative Antimicrobial Activity of Commercial Wound Care Solutions on Bacterial and Fungal Biofilms. Ann. Plast. Surg. 2019, 83, 404-410. [CrossRef] [PubMed]

6. Negut, I.; Grumezescu, V.; Grumezescu, A.M. Treatment strategies for infected wounds. Molecules 2018, 23, 2392. [CrossRef] [PubMed]

7. Borkow, G.; Gabbay, J.; Zatcoff, R.C. Could chronic wounds not heal due to too low local copper levels? Med. Hypotheses 2008, 70, 610-613. [CrossRef]

8. Bajpai, S.K.; Pathak, V.; Soni, B. Minocycline-loaded cellulose nano whiskers/poly(sodium acrylate) composite hydrogel films as wound dressing. Int. J. Biol. Macromol. 2015, 79, 76-85. [CrossRef]

9. Gharibi, R.; Kazemi, S.; Yeganeh, H.; Tafakori, V. Utilizing dextran to improve hemocompatibility of antimicrobial wound dressings with embedded quaternary ammonium salts. Int. J. Biol. Macromol. 2019, 131, 1044-1056. [CrossRef]

10. Mishra, S.K.; Mary, D.S.; Kannan, S. Copper incorporated microporous chitosan-polyethylene glycol hydrogels loaded with naproxen for effective drug release and anti-infection wound dressing. Int. J. Biol. Macromol. 2017, 95, 928-937. [CrossRef]

11. Rizani, N. Modern Wound Dressing for Wound Infection: An Overview. Indones. J. Trop. Infect. Dis. 2015, 3, 39. [CrossRef]

12. Ye, S.; Jiang, L.; Wu, J.; Su, C.; Huang, C.; Liu, X.; Shao, W. Flexible Amoxicillin-Grafted Bacterial Cellulose Sponges for Wound Dressing: In Vitro and in Vivo Evaluation. ACS Appl. Mater. Interfaces 2018, 10, 5862-5870. [CrossRef] [PubMed]

13. Eberlein, T.; Haemmerle, G.; Signer, M.; Gruber-Moesenbacher, U.; Traber, J.; Mittlboeck, M.; Abel, M.; Strohal, R. Comparison of PHMB-containing dressing and silver dressings in patients with critically colonised or locally infected wounds. J. Wound Care 2012, 21, 12-20. [CrossRef] [PubMed]

14. Loke, W.K.; Lau, S.K.; Yong, L.L.; Khor, E.; Sum, C.K. Wound dressing with sustained anti-microbial capability. J. Biomed. Mater. Res. 2000, 53, 8-17. [CrossRef]

15. Basu, A.; Heitz, K.; Strømme, M.; Welch, K.; Ferraz, N. Ion-crosslinked wood-derived nanocellulose hydrogels with tunable antibacterial properties: Candidate materials for advanced wound care applications. Carbohydr. Polym. 2018, 181, 345-350. [CrossRef]

16. Klinkajon, W.; Supaphol, P. Novel copper (II) alginate hydrogels and their potential for use as anti-bacterial wound dressings. Biomed. Mater. 2014, 9, 045008. [CrossRef]

17. Muwaffak, Z.; Goyanes, A.; Clark, V.; Basit, A.W.; Hilton, S.T.; Gaisford, S. Patient-specific 3D scanned and 3D printed antimicrobial polycaprolactone wound dressings. Int. J. Pharm. 2017, 527, 161-170. [CrossRef]

18. Kornblatt, A.P.; Nicoletti, V.G.; Travaglia, A. The neglected role of copper ions in wound healing. J. Inorg. Biochem. 2016, 161, 1-8. [CrossRef]

19. Li, P.; Feng, Z.; Yu, Z.; Chen, Y.; Li, P.; Yang, Z.; Li, S.; Jin, S. Preparation of chitosan-Cu ${ }^{2+} / \mathrm{NH}_{3}$ physical hydrogel and its properties. Int. J. Biol. Macromol. 2019, 133, 67-75. [CrossRef]

20. Yang, J.J.; Huang, Y.C.; Chuang, T.H.; Herr, D.R.; Hsieh, M.F.; Huang, C.J.; Huang, C.M. Cysteine-capped hydrogels incorporating copper as effective antimicrobial materials against methicillin-resistant staphylococcus aureus. Microorganisms 2020, 8, 149. [CrossRef] 
21. Ren, X.; Yang, C.; Zhang, L.; Li, S.; Shi, S.; Wang, R.; Zhang, X.; Yue, T.; Sun, J.; Wang, J. Copper metal-organic frameworks loaded on chitosan film for the efficient inhibition of bacteria and local infection therapy. Nanoscale 2019, 11, 11830-11838. [CrossRef] [PubMed]

22. Zhang, R.; Edgar, K.J. Properties, chemistry, and applications of the bioactive polysaccharide curdlan. Biomacromolecules 2014, 15, 1079-1096. [CrossRef] [PubMed]

23. Klimek, K.; Przekora, A.; Pałka, K.; Ginalska, G. New method for the fabrication of highly osteoconductive $\beta$-1,3-glucan/HA scaffold for bone tissue engineering: Structural, mechanical, and biological characterization. J. Biomed. Mater. Res. Part A 2016, 104A, 2528-2536. [CrossRef] [PubMed]

24. Sato, M.; Nobe, M.; Dobashi, T.; Yamamoto, T.; Konno, A. Multifold curdlan gel formation by dialysis into aqueous solutions of metal salts. Colloid Polym. Sci. 2005, 284, 293-300. [CrossRef]

25. Klimek, K.; Benko, A.; Pałka, K.; Ludwiczuk, A.; Ginalska, G. Ion-exchanging dialysis as an effective method for protein entrapment in curdlan hydrogel. Mater. Sci. Eng. C 2019, 105, 110025. [CrossRef]

26. Klimek, K.; Przekora, A.; Benko, A.; Niemiec, W.; Blazewicz, M.; Ginalska, G. The use of calcium ions instead of heat treatment for $\beta$-1,3-glucan gelation improves biocompatibility of the $\beta$-1,3-glucan/HA bone scaffold. Carbohydr. Polym. 2017, 164, 170-178. [CrossRef]

27. Rezvanian, M.; Ahmad, N.; Cairul, M.; Mohd, I.; Ng, S. Optimization, characterization, and in vitro assessment of alginate-pectin ionic cross-linked hydrogel film for wound dressing applications. Int. J. Biol. Macromol. 2017, 97, 131-140. [CrossRef]

28. Rezvanian, M.; Cairul, M.; Mohd, I.; Ng, S. Development and physicochemical characterization of alginate composite film loaded with simvastatin as a potential wound dressing. Carbohydr. Polym. 2016, 137, $295-304$. [CrossRef]

29. ISO 10993-5:2009, Biological Evaluation of Medical Devices-Part 5: Tests for In Vitro Cytotoxicity; International Organization for Standarization: Geneva, Switzerland, 2009.

30. Kowalczuk, D.; Ginalska, G.; Piersiak, T.; Miazga-Karska, M. Prevention of biofilm formation on urinary catheters: Comparison of the sparfloxacin-treated long-term antimicrobial catheters with silver-coated ones. J. Biomed. Mater. Res. Part B Appl. Biomater. 2012, 100B, 1874-1882. [CrossRef]

31. Siek, D.; Ślósarczyk, A.; Przekora, A.; Belcarz, A.; Zima, A.; Ginalska, G.; Czechowska, J. Evaluation of antibacterial activity and cytocompatibility of $\alpha$-TCP based bone cements with silver-doped hydroxyapatite and CaCO3. Ceram. Int. 2017, 43, 13997-14007. [CrossRef]

32. Klimek, K.; Strubińska, J.; Czernel, G.; Ginalska, G.; Gagoś, M. In vitro evaluation of antifungal and cytotoxic activities as also the therapeutic safety of the oxidized form of amphotericin B. Chem. Biol. Interact. 2016, 256. [CrossRef] [PubMed]

33. Cao, D.; Zhang, Y.; Cui, Z.; Du, Y.; Shi, Z. New strategy for design and fabrication of polymer hydrogel with tunable porosity as artificial corneal skirt. Mater. Sci. Eng. C 2017, 70, 665-672. [CrossRef] [PubMed]

34. Koehler, J.; Brandl, F.P.; Goepferich, A.M. Hydrogel wound dressings for bioactive treatment of acute and chronic wounds. Eur. Polym. J. 2018, 100, 1-11. [CrossRef]

35. Tyeb, S.; Kumar, N.; Kumar, A.; Verma, V. Flexible agar-sericin hydrogel film dressing for chronic wounds. Carbohydr. Polym. 2018, 200, 572-582. [CrossRef] [PubMed]

36. Elsner, J.J.; Zilberman, M. Novel antibiotic-eluting wound dressings: An in vitro study and engineering aspects in the dressing's design. J. Tissue Viability 2010, 19, 54-66. [CrossRef]

37. Przekora, A. Current trends in fabrication of biomaterials for bone and cartilage regeneration: Materials modifications and biophysical stimulations. Int. J. Mol. Sci. 2019, 20, 435. [CrossRef]

38. Jaganathan, S.K.; Mani, M.P.; Khudzari, A.Z.M. Electrospun combination of peppermint oil and copper sulphate with conducive physico-chemical properties for wound dressing applications. Polymers 2019, 11, 586. [CrossRef]

(C) 2020 by the authors. Licensee MDPI, Basel, Switzerland. This article is an open access article distributed under the terms and conditions of the Creative Commons Attribution (CC BY) license (http://creativecommons.org/licenses/by/4.0/). 